\title{
Modeling of the Penultimate Unit Effect in Chain- Growth Copolymerizations
}

\author{
Fabricio Machado ${ }^{1,2}$ \\ ${ }^{1}$ Instituto de Química, Universidade de Brasília, Campus Universitário Darcy Ribeiro, CEP: 70910-900 Brasília, DF, Brazil \\ ${ }^{2}$ Programa de Pós-Graduação em Engenharia Química, Universidade Federal de Goiás, CEP: 74690-900 Goiânia, GO, Brazil \\ Correspondence should be addressed to Fabricio Machado; fmachado@unb.br
}

Received 17 January 2019; Accepted 26 March 2019; Published 28 April 2019

Academic Editor: Mehdi Salami-Kalajahi

Copyright (C) 2019 Fabricio Machado. This is an open access article distributed under the Creative Commons Attribution License, which permits unrestricted use, distribution, and reproduction in any medium, provided the original work is properly cited.

\begin{abstract}
The present work addresses the modeling and simulation of the addition of copolymerizations of styrene and methyl methacrylate in batch mode, and the formation of tailored vinyl acetate/acrylic acid copolymers is evaluated through stochastic optimization procedures based on the Monte Carlo method. A kinetic model of the free-radical reaction was proposed in order to predict the behavior of the reaction system taking into consideration the presence of the penultimate unit effect. The profiles of conversion and copolymer composition were also evaluated considering the effect of the medium viscosity (kinetic phenomena related to gel and glass effects) on the reaction performance. It was shown that the proposed model for chain-growth copolymerization is able to describe strong nonlinear behaviors such as autoacceleration of the polymerization and drift of copolymer composition. It was also shown that copolymers with homogeneous composition can be successfully synthesized through manipulation of the monomer feed flow rate based on a stochastic optimization procedure.
\end{abstract}

\section{Introduction}

It is well-known that all reaction mechanism steps play an important role for the determination of copolymerization kinetic behavior. Despite this, the propagation step is fundamental for the proper description of the overall propagation rate coefficients, of polymer composition, and of the sequence distribution of final copolymer, important properties that define the material polymeric application.

In chain-growth polymerizations, two propagation models are normally used to describe the polymerization. The first one is the well-known terminal model [1], which assumes that the reactivity of the propagation reaction is governed only by the nature of the monomer and of the terminal unit of the growing polymer chain. The second one is known as the penultimate model [2], which considers the effect of both the terminal and penultimate monomeric units of the growing polymer chain. According to this assumption, electronic and geometric effects or steric interactions between the penultimate monomeric unit and reactant species (e.g., monomers, transfer agents, and solvents) can be incorporated into the propagation model $[3,4]$. As a consequence, one has to keep in mind that the penultimate model normally leads to a considerable increase in the number of model parameters, and for this reason, the terminal model is the most popular propagation model and is the starting point for most studies on polymerization kinetics.

The penultimate model is generally employed when the terminal model (first-order Markovian model) is not able to satisfactorily describe polymerization rates. Two types of the penultimate model have been proposed: (i) the first one is named the explicit penultimate model which assumes that both the terminal and penultimate units of the radical can affect both the reactivity and selectivity; (ii) the second one denominated the implicit penultimate model which considers that despite the terminal and penultimate units of the polymeric radical affect the reactivity, only the terminal unit affects the selectivity [5-13].

Coote and Davis [6] presented an extensive list of monomeric pairs, where the terminal model is not suitable to describe copolymerization kinetic, and the reader is referred to this publication for more detailed information. Although 
the penultimate effect is important to describe both the composition and the polymerization kinetics in several polymer systems, only few kinetic parameters for the penultimate model are reported in the open literature. Recently, Deb [14] calculated the penultimate model reactivity ratios from different binary monomer mixtures employed in copolymerization systems.

Typically, polymerization systems comprising styrene/acrylonitrile [15-20], methyl methacrylate/n-butyl acrylate [21], ethylene/styrene [22], dimethyl itaconate/styrene [23], ethylene/4-methyl-1-pentene [24], $\alpha$-alkylstyrenes/acrylonitrile [25], styrene/methyl methacrylate [26], p-chlorostyrene/methyl acrylate [27], styrene/isobutylene [28], methyl $\alpha$ (trifluoromethyl)acrylate and $\alpha$-(trifluoromethyl) acrylonitrile with styrene, p-chlorostyrene and methyl methacrylate [29], styrene/maleic anhydride [30], isobutyl methacrylate/lauryl methacrylate [31], and styrene/fumaronitrile [32, 33] demonstrate a strong penultimate unit effect, representing good examples of the successful implementation of the penultimate model $[9,34]$.

The kinetic mechanism represented by the penultimate model (second-order Markovian model) is composed of four distinct radicals that can combine with monomeric species, generating eight distinct stages of propagation $\left(\sim M_{i j}+M_{n} \longrightarrow^{k_{i j n}} \sim M_{i j n}\right.$ with $i, j, n=1,2$, where $k_{i j n}$ is the reaction rate constant that characterizes the addition of the monomer unit $n$ to a growing polymer chain containing the monomeric units $i$ and $j$ ). Given the complex nature of polymerization systems, the introduction of additional stages of propagation with a consequent increase in the number of kinetic parameters is the major practical limitation of employing the penultimate model in polymerization kinetic models intended to be used to describe the reaction behavior.

In spite of the popularity of the terminal model, it is generally agreed that the existence of the penultimate unit effect in important chain-growth polymerization systems seems to be general rather than an exception, which clearly indicates that this polymerization kinetic based on the terminal model oversimplifies actual polymerization reaction processes [8, 14]. Initial studies on the influence of the penultimate unit effect in free-radical copolymerizations date from 1940s. Among then, the pioneering works of Merz et al. [2], Barb [30], and Ham [33] must be highlighted.

The penultimate model was originally developed by Merz et al. [2] to predict the copolymer composition and sequence distribution of the final copolymer. This propagation model was extensively explored by Fukuda and coworkers [5, 9, $26,27]$, some years later, in order to understand the deviations from the terminal model, showing that the penultimate model provides a good description of copolymer composition, distribution sequences, and rate of propagation. Fukuda and coworkers have distinguished the penultimate unit effect behavior, originating two distinct models: explicit penultimate and implicit penultimate models of copolymerization. Fukuda et al. [26] also demonstrated through measurements of average propagation rate constant from copolymerizations of styrene/methyl methacrylate that the terminal model was not suitable to appropriately describe the experimental data.
Li et al. $[35,36]$ have described the combined effect of depropagation and penultimate unit effect kinetic on the instantaneous copolymer composition and average copolymerization rate coefficients in styrene/butyl methacrylate reactions performed at elevated temperatures. According to the authors, when depropagation appears combined with the penultimate unit effect, the effective propagation rate coefficient deviates significantly from terminal model predictions regarding the copolymer composition.

Recently, Nikitin and Hutchinson [37] have evaluated the penultimate unit effect in homopolymerization of acrylates. According to the proposed kinetic mechanism, the differences in reactivity of radicals formed by monomer addition to midchain radicals are taking into consideration. Model calculations have shown that deviation from the terminal model may depend on the radical reactivity ratio $s_{i}$ and monomer concentrations, which generally complicates the kinetic analysis of acrylate homopolymerizations.

In the present work, a phenomenological polymerization model is proposed based on the kinetic mechanism that takes into account the penultimate monomeric unit effect in chaingrowth copolymerizations and simulations are performed based on a typical polymerization system (styrene/methyl methacrylate) governed by the penultimate kinetic model. Additionally, the penultimate model is also employed to describe the experimental data of vinyl acetate/acrylic acid suspension copolymerization carried out in a batch mode. It is also proposed strategies for controlling the copolymer composition based on stochastic optimization procedures with the Monte Carlo method.

\section{Kinetic Mechanism and Polymerization Model}

The kinetic mechanism proposed to describe the (e.g., bulk or suspension) copolymerizations comprises the following fundamental steps: initiation, propagation, transfer to monomer, and termination by disproportionation and combination, as follows:

Step 1. Initiation

$$
\begin{array}{r}
I \stackrel{k_{D}}{\longrightarrow} 2 Z, \\
Z+M_{1} \stackrel{k_{1}}{\rightarrow} P_{1,0}, \\
Z+M_{2} \stackrel{k_{2}}{\rightarrow} S_{0,1} .
\end{array}
$$

Step 2. Propagation

$$
\begin{gathered}
P_{i, j}+M_{1} \stackrel{k_{P_{111}}}{\longrightarrow} P_{i+1, j}, \\
P_{i, j}+M_{2} \stackrel{k_{P_{112}}}{\longrightarrow} Q_{i, j+1}, \\
Q_{i, j}+M_{1} \stackrel{k_{P_{121}}}{\longrightarrow} R_{i+1, j}, \\
Q_{i, j}+M_{2} \stackrel{k_{P_{122}}}{\longrightarrow} S_{i, j+1},
\end{gathered}
$$




$$
\begin{aligned}
& R_{i, j}+M_{1} \stackrel{k_{P_{211}}}{\longrightarrow} P_{i+1, j}, \\
& R_{i, j}+M_{2} \stackrel{k_{P_{212}}}{\longrightarrow} Q_{i, j+1}, \\
& S_{i, j}+M_{1} \stackrel{k_{P_{221}}}{\longrightarrow} R_{i+1, j}, \\
& S_{i, j}+M_{2} \stackrel{k_{P_{222}}}{\longrightarrow} S_{i, j+1} .
\end{aligned}
$$

Step 3. Transfer to monomer

$$
\begin{gathered}
P_{i, j}+M_{1} \stackrel{k_{t r_{M 111}}}{\longrightarrow} \Theta_{i, j}+P_{1,0}, \\
P_{i, j}+M_{2} \stackrel{{ }_{t r_{M 112}}}{\longrightarrow} \Theta_{i, j}+S_{0,1}, \\
Q_{i, j}+M_{1} \stackrel{k_{t r_{M 121}}}{\longrightarrow} \Theta_{i, j}+P_{1,0}, \\
Q_{i, j}+M_{2} \stackrel{k_{t r_{M 122}}}{\longrightarrow} \Theta_{i, j}+S_{0,1}, \\
R_{i, j}+M_{1} \stackrel{k_{t r_{M 211}}}{\longrightarrow} \Theta_{i, j}+P_{1,0}, \\
R_{i, j}+M_{2} \stackrel{{ }_{t r_{M 212}}}{\longrightarrow} \Theta_{i, j}+S_{0,1}, \\
S_{i, j}+M_{1} \stackrel{{ }_{t r_{M 221}}}{\longrightarrow} \Theta_{i, j}+P_{1,0}, \\
S_{i, j}+M_{2} \stackrel{k_{t r_{M 222}}}{\longrightarrow} \Theta_{i, j}+S_{0,1} .
\end{gathered}
$$

Step 4. Termination by disproportionation

$$
\begin{gathered}
P_{i, j}+P_{m, n} \stackrel{k_{T D_{11}}}{\longrightarrow} \Theta_{i, j}+\Theta_{m, n}, \\
P_{i, j}+Q_{m, n} \stackrel{k_{T D_{12}}}{\longrightarrow} \Theta_{i, j}+\Theta_{m, n}, \\
P_{i, j}+R_{m, n} \stackrel{k_{T D_{13}}}{\longrightarrow} \Theta_{i, j}+\Theta_{m, n}, \\
P_{i, j}+S_{m, n} \stackrel{k_{T D_{14}}^{\longrightarrow}}{\longrightarrow} \Theta_{i, j}+\Theta_{m, n}, \\
Q_{i, j}+Q_{m, n} \stackrel{k_{T D_{22}}^{\longrightarrow}}{\longrightarrow} \Theta_{i, j}+\Theta_{m, n}, \\
Q_{i, j}+R_{m, n} \stackrel{k_{T D_{23}}^{\longrightarrow}}{\longrightarrow} \Theta_{i, j}+\Theta_{m, n}, \\
Q_{i, j}+S_{m, n} \stackrel{k_{T D_{24}}^{\longrightarrow}}{\longrightarrow} \Theta_{i, j}+\Theta_{m, n}, \\
R_{i, j}+R_{m, n} \stackrel{k_{T D_{33}}^{\longrightarrow}}{\longrightarrow} \Theta_{i, j}+\Theta_{m, n}, \\
R_{i, j}+S_{m, n} \stackrel{k_{T D_{34}}^{\longrightarrow}}{\longrightarrow} \Theta_{i, j}+\Theta_{m, n}, \\
S_{i, j}+S_{m, n} \stackrel{k_{T D_{44}}^{\longrightarrow}}{\longrightarrow} \Theta_{i, j}+\Theta_{m, n} .
\end{gathered}
$$

Step 5. Termination by combination

$$
\begin{gathered}
P_{i, j}+P_{m, n} \stackrel{k_{T C_{11}}}{\longrightarrow} \Theta_{i+m, j+n}, \\
P_{i, j}+Q_{m, n} \stackrel{k_{T C_{12}}}{\longrightarrow} \Theta_{i+m, j+n}, \\
P_{i, j}+R_{m, n} \stackrel{k_{T C_{13}}}{\longrightarrow} \Theta_{i+m, j+n}, \\
P_{i, j}+S_{m, n} \stackrel{k_{T C_{14}}}{\longrightarrow} \Theta_{i+m, j+n}, \\
Q_{i, j}+Q_{m, n} \stackrel{k_{T C_{22}}}{\longrightarrow} \Theta_{i+m, j+n}, \\
Q_{i, j}+R_{m, n} \stackrel{k_{T C_{23}}}{\longrightarrow} \Theta_{i+m, j+n}, \\
Q_{i, j}+S_{m, n} \stackrel{k_{T C_{24}}}{\longrightarrow} \Theta_{i+m, j+n}, \\
R_{i, j}+R_{m, n} \stackrel{k_{T C_{33}}}{\longrightarrow} \Theta_{i+m, j+n}, \\
R_{i, j}+S_{m, n} \stackrel{k_{T C_{34}}}{\longrightarrow} \Theta_{i+m, j+n}, \\
S_{i, j}+S_{m, n} \stackrel{k_{T C_{44}}}{\longrightarrow} \Theta_{i+m, j+n}, \\
P=\sum_{i=1}^{\infty} \sum_{j=0}^{\infty} P_{i, j}, \\
Q=\sum_{i=0}^{\infty} \sum_{j=1}^{\infty} Q_{i, j}, \\
\sum_{i=1}^{\infty} \sum_{j=0}^{\infty} R_{i, j}, \\
S_{i, j}, \\
P_{j=1}^{\infty},
\end{gathered}
$$

where $I$ is the concentration of the initiator; $k_{D}$ is the kinetic constant for initiator decomposition; $Z$ is the concentration of free radical of the initiator; $M_{i}$ is the concentration of monomer $i ; k_{i}$ is the kinetic constant for the formation of the first polymeric radical $i ; P_{1,0}$ is the first polymeric radical containing 1 mer of species $1 ; Q_{0,1}$ is the first polymeric radical containing 1 mer of species 2; $k_{P_{i j l}}$ is the kinetic constant for the propagation of polymeric radical containing the monomeric units $i$ (penultimate) and $j$ (terminal) with monomer unit $l ; P_{i, j}$ is the growing polymeric chain containing the meric units $i$ and $j$ and species 1 at the active site (polymeric radical $1-[P]=\sim M_{1} M_{1} \cdot$ ); $Q_{i, j}$ is the growing polymeric chain containing the meric units $i$ and $j$ and species 2 at the active site (polymer radical $\left.2-[Q]=\sim M_{1} M_{2} \cdot\right) ; R_{i, j}$ is the growing polymeric chain containing the meric units $i$ and $j$ and species 1 at the active site $\left([R]=\sim M_{2} M_{1} \cdot\right) ; S_{i, j}$ is the growing polymeric chain containing the meric units $i$ and $j$ and species 2 at the active site ( $\left.[S]=\sim M_{2} M_{2} \cdot\right) ; \Theta_{i, j}$ is the dead polymer chain containing mer units $i$ and $j ; k_{t r M_{i j l}}$ is the kinetic constant of transfer of 
polymeric radical containing the monomeric units $i$ and $j$ to monomer $l ; k_{T D_{i j}}$ and $k_{T C_{i j}}$ are the kinetic constants for termination by disproportionation and combination of growing polymeric radicals $i$ and $j$, respectively; $P, Q, R$, and $S$ represent the total concentration of growing polymeric radicals; $k_{T_{i j}}$ is the kinetic constant that characterizes the combined contribution of the termination by both disproportionation and combination $\left(k_{T_{i j}}=k_{T D_{i j}}+k_{T C_{i j}}\right)$; and $f$ is the initiator efficiency.

According to the proposed kinetic mechanism and assuming that the long-chain and quasi-steady-state hypotheses are valid for the polymer radicals and admitting that the propagation terms are much larger than the initiation, chain transfer, and termination terms, it is possible to write the following set of mass balance equations for the copolymerization process:

$$
\begin{aligned}
\frac{d I}{d t} & =-k_{D} I, \\
\frac{d M_{1}}{d t} & =-\left(k_{P_{111}} P\right)\left[1+\Omega\left(\frac{1}{r_{11}}+\frac{r_{12}}{r_{11}} \frac{M_{2}}{M_{1}}\right)+\frac{M_{2}}{r_{11} M_{1}}\right] M_{1}, \\
\frac{d M_{2}}{d t} & =-\left(k_{P_{111}} P\right)\left[\frac{1}{r_{11}}+\Omega\left(\frac{r_{12}}{r_{11}}+\frac{r_{22} r_{12}}{r_{11}} \frac{M_{2}}{M_{1}}\right)+\frac{M_{2}}{r_{21} r_{11} M_{1}}\right] M_{2}, \\
\frac{d \wp_{1}}{d t} & =\left(k_{P_{111}} P\right)\left[1+\Omega\left(\frac{1}{r_{11}}+\frac{r_{12}}{r_{11}} \frac{M_{2}}{M_{1}}\right)+\frac{M_{2}}{r_{11} M_{1}}\right] M_{1}, \\
\frac{d \wp_{2}}{d t} & =\left(k_{P_{111}} P\right)\left[\frac{1}{r_{11}}+\Omega\left(\frac{r_{12}}{r_{11}}+\frac{r_{22} r_{12}}{r_{11}} \frac{M_{2}}{M_{1}}\right)+\frac{M_{2}}{r_{21} r_{11} M_{1}}\right] M_{2},
\end{aligned}
$$

where

$$
\begin{aligned}
\Omega= & \left(\frac{M_{2}+\left(1 / r_{21}\right)\left(M_{2}^{2} / M_{1}\right)}{M_{1}+r_{12} M_{2}}\right), \\
& r_{i i}=\frac{k_{P_{i i i}}}{k_{P_{i i j}}}, r_{i j}=\frac{k_{P_{i j j}}}{k_{P_{i j i}}}, s_{i}=\frac{k_{P_{j i i}}}{k_{P_{i i i}}}, i=1,2(i \neq j), \\
\left(k_{P_{111}} P\right)= & \left\{2 f k _ { D } I \left[\frac{1}{\psi_{11}}+\frac{1}{\psi_{22}}\left(\Omega \frac{r_{12}}{s_{2} r_{11}}\right)^{2}+\frac{1}{\psi_{33}}\left(\frac{M_{2}}{s_{1} r_{11} M_{1}}\right)^{2}\right.\right. \\
& +\frac{1}{\psi_{44}}\left(\Omega \frac{r_{12} r_{22} M_{2}}{r_{11} M_{1}}\right)^{2}+\frac{2 \Omega \zeta_{12}}{\sqrt{\psi_{11} \psi_{22}}} \frac{r_{12}}{s_{2} r_{11}} \\
& +\frac{2 \zeta_{13}}{\sqrt{\psi_{11} \psi_{33}}} \frac{M_{2}}{s_{1} r_{11} M_{1}}+\frac{2 \Omega \zeta_{14}}{\sqrt{\psi_{11} \psi_{44}}} \frac{r_{12} r_{22} M_{2}}{r_{11} M_{1}} \\
& +\frac{2 \Omega \zeta_{23}}{\sqrt{\psi_{22} \psi_{33}}} \frac{r_{12} M_{2}}{s_{1} s_{2} r_{11}^{2} M_{1}}+\frac{2 \Omega^{2} \zeta_{24}}{\sqrt{\psi_{22} \psi_{44}}} \frac{r_{12}^{2} r_{22} M_{2}}{s_{2} r_{11}^{2} M_{1}} \\
& \left.\left.+\frac{2 \Omega \zeta_{34}}{\sqrt{\psi_{33} \psi_{44}}} \frac{r_{12} r_{22}}{s_{1} r_{11}^{2}}\left(\frac{M_{2}}{M_{1}}\right)^{2}\right]^{-1}\right\}^{1 / 2}
\end{aligned}
$$

$$
\begin{aligned}
& \zeta_{i j}=\frac{k_{T_{i j}}}{\sqrt{k_{T_{i i}} k_{T_{j j}}}}, \quad i=1,2, j=2,4(i \neq j), \\
& \psi_{i i}=\frac{k_{P_{i i i}}{ }^{2}}{k_{T_{i i}}}, \quad i=1,2(i \neq j), \\
& \psi_{j j}=\frac{k_{P_{i i i}}{ }^{2}}{k_{T_{j j}}}, \quad i=1,2, j=3,4,
\end{aligned}
$$

where $r_{i j}$ is the reactivity ratio monomers $i$ and $j, s_{i}$ is the radical reactivity ratios for growing polymer chain $i, \zeta_{i j}$ is the cross-termination constant between polymer radicals $i$ and $j$, and $\wp_{i}$ is the moles of monomer $i$ incorporated into polymer chains.

\section{Results and Discussion}

3.1. Styrene/Methyl Methacrylate Copolymerization. Figure 1 shows the simulation result for the styrene (S)/methyl methacrylate (MMA) system, which is considered a typical polymerization where the penultimate effect has to be taken into account. All model parameters (see equations (6) and (7) and Table 1) used for simulations were obtained from Schmidt and Ray [38], Kalfas et al. [39], and Burke et al. [34], and the reader is referred to these works for more detailed information. Copolymerization model equations were implemented in FORTRAN and solved numerically with the integration package DDASSL [40]. A maximum reaction conversion of approximately $92 \%$ at the end of the reaction with a molar fraction of styrene in the copolymer equal to $17 \%$, which is kept almost constant along the reaction time (Figure 1(b)) and reaction conversion (Figure 1(a)), is observed.

It is generally agreed that viscosity effects play a fundamental role in free-radical polymerization reactions, leading to strong diffusion limitations in the reaction medium. This particular and relevant nonlinear kinetic phenomenon is characterized by the glass and gel effects.

Additionally, for simulations of polymerization systems where glass and gel effects play a significant role, it is very important to consider correlations adopted to correct the propagation $\left[k_{P_{i i i}}^{f v}=k_{P_{i i i}} g_{P_{i}}(T)\right]$ and termination $\left[k_{T_{i i i}}^{f v}=k_{T_{i i i}}\right.$ $\left.g_{T_{i}}(T)\right]$ constant deviations due to the diffusion limitations of both the monomer and growth polymer chain species. In this scenario, correlations based on the free volume theory are of fundamental importance [41].

It is widely adopted that the free volume of the polymerization system $\left(v_{f}\right)$ can be expressed as the sum of the individual contribution of each species $\left(v_{f_{i}}\right)$, as follows [38]:

$$
v_{f}=\sum_{i} v_{f_{i}} \phi_{i}
$$




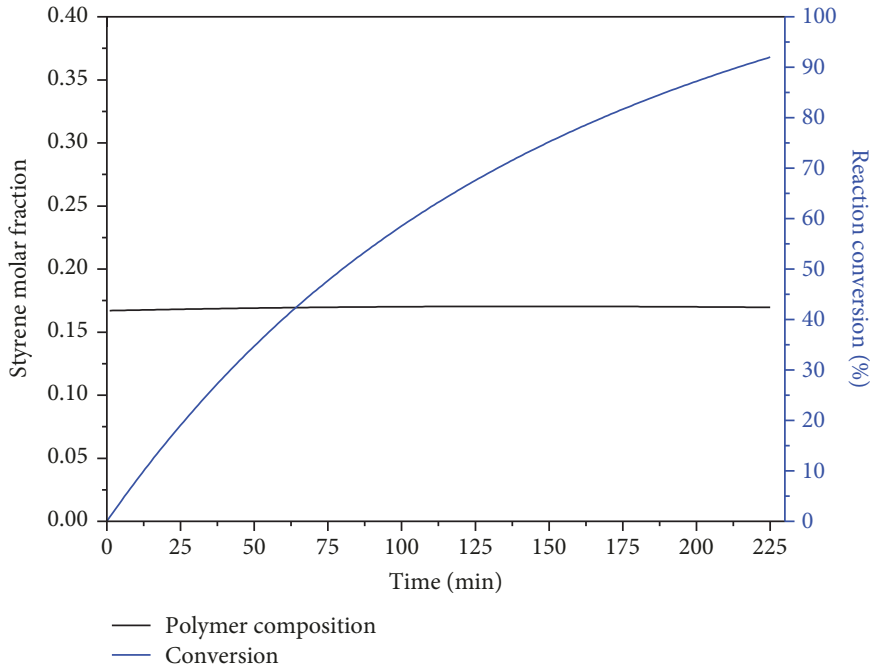

(a)

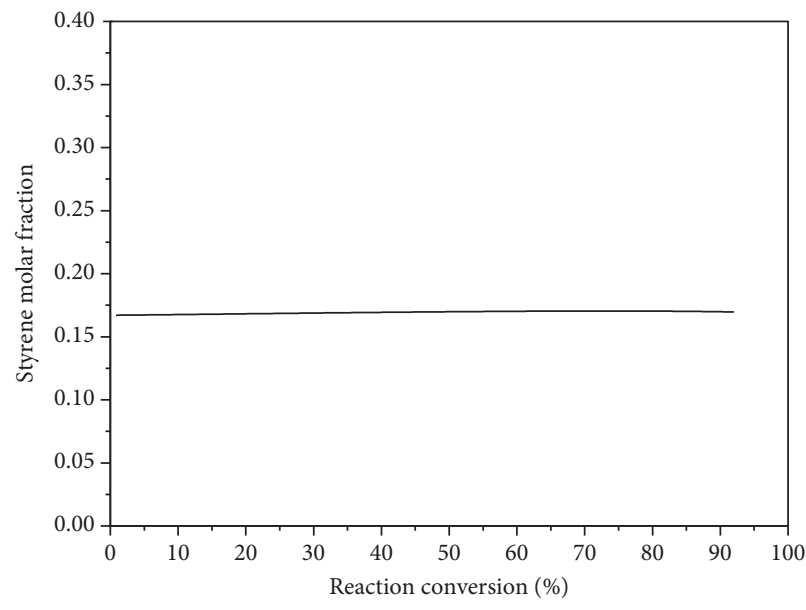

(b)

Figure 1: Conversion and copolymer composition profiles. $I=0.17 \mathrm{~mol}, M_{1}=1.54 \mathrm{~mol}, M_{2}=5.00 \mathrm{~mol}, T=85^{\circ} \mathrm{C}, r_{11}=0.472, r_{12}=0.454$, $r_{21}=0.472, r_{22}=0.454, s_{1}=0.412$, and $s_{2}=0.170[34]$.

TABLE 1: Model parameters used for simulation of styrene/methyl methacrylate system.

\begin{tabular}{|c|c|c|}
\hline Parameter & Unit & Reference \\
\hline$\rho_{1}=0.9193-6.65 \cdot 10^{-4}(T-273.15)$ & $\mathrm{g} / \mathrm{cm}^{3}$ & {$[39]$} \\
\hline$\rho_{2}=0.9654-1.09 \cdot 10^{-3}(T-273.15)-0.970 \cdot 10^{-6}(T-273.15)^{2}$ & $\mathrm{~g} / \mathrm{cm}^{3}$ & {$[39]$} \\
\hline$\rho_{3}=0.9926-2.65 \cdot 10^{-4}(T-273.15)$ & $\mathrm{g} / \mathrm{cm}^{3}$ & {$[39]$} \\
\hline$\rho_{4}=1.18-0.10 \cdot 10^{-2}(T-273.15)$ & $\mathrm{g} / \mathrm{cm}^{3}$ & {$[39]$} \\
\hline$k_{P_{111}}=1.090 \times 10^{7} \exp (-7051 / R T)$ & $\mathrm{L} /(\mathrm{mol} \cdot \mathrm{s})$ & [34] \\
\hline$k_{T_{111}}=1.703 \times 10^{9} \exp (-2268 / R T)$ & $\mathrm{L} /(\mathrm{mol} \cdot \mathrm{s})$ & [34] \\
\hline$k_{P_{222}}=5.366 \times 10^{5} \exp (-4353 / R T)$ & $\mathrm{L} /(\mathrm{mol} \cdot \mathrm{s})$ & {$[34]$} \\
\hline$k_{T_{222}}=9.800 \times 10^{7} \exp (-701 / R T)$ & $\mathrm{L} /(\mathrm{mol} \cdot \mathrm{s})$ & {$[34]$} \\
\hline$k_{D}=1.7 \times 10^{14} \exp (-30000 / R T)$ & $\mathrm{s}^{-1}$ & [39] \\
\hline$f=0.80$ & - & {$[48]$} \\
\hline
\end{tabular}

Subscript 1 for styrene and 2 for methyl methacrylate; subscripts 3 and 4 for the homopolymers based on styrene and methyl methacrylate, respectively.

The free volume contribution of methyl methacrylate $\left(v_{f_{\mathrm{MMA}}}\right)$ and its homopolymer $\left(v_{f_{\mathrm{PMMA}}}\right)$ is proposed by Schmidt and Ray [38] in the following form:

$$
\begin{gathered}
v_{f_{\mathrm{MMA}}}=0.025+0.0010(T-167.15), \\
v_{f_{\mathrm{PMMA}}}=0.025+0.00048(T-387.15),
\end{gathered}
$$

$$
\phi_{i}=\frac{\rho_{i} / m_{i}}{\sum_{i} \rho_{i} / m_{i}}
$$

where $\rho_{i}$ is the pure density of species $i$ and $m_{i}$ is the mass of species $i$. It is also assumed that $g_{T_{\mathrm{MMA}}}(T)$ can be expressed as $[38,39,42]$

$$
g_{T_{\mathrm{MMA}}}(T)= \begin{cases}0.10575 \exp \left[17.15 v_{f}-0.01715(T-273.15)\right], & \text { for } v_{f}>v_{f_{c}}^{T}, \\ 2.3 \cdot 10^{-6} \exp \left(75 v_{f}\right), \quad \text { for } v_{f} \leq v_{f_{c}}^{T},\end{cases}
$$




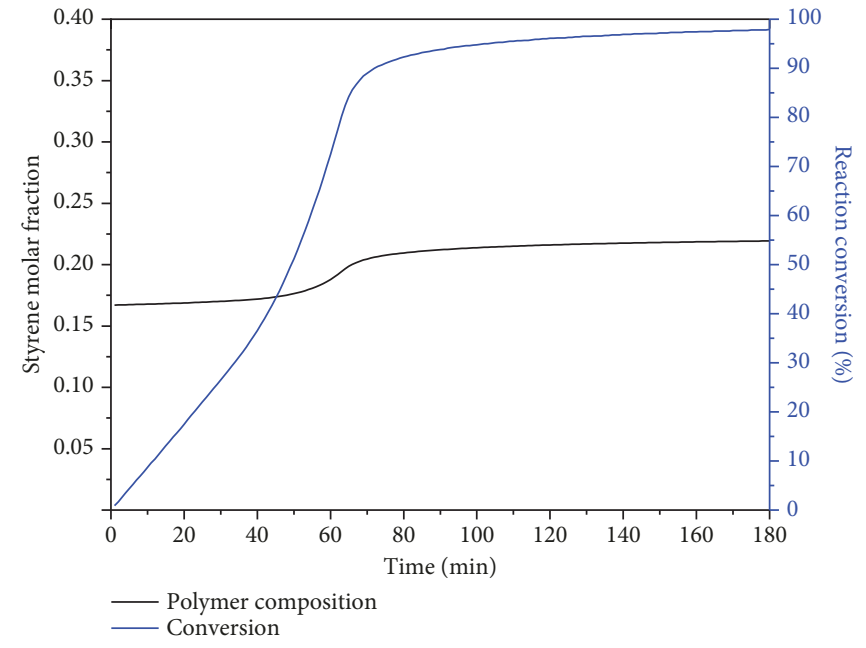

(a)

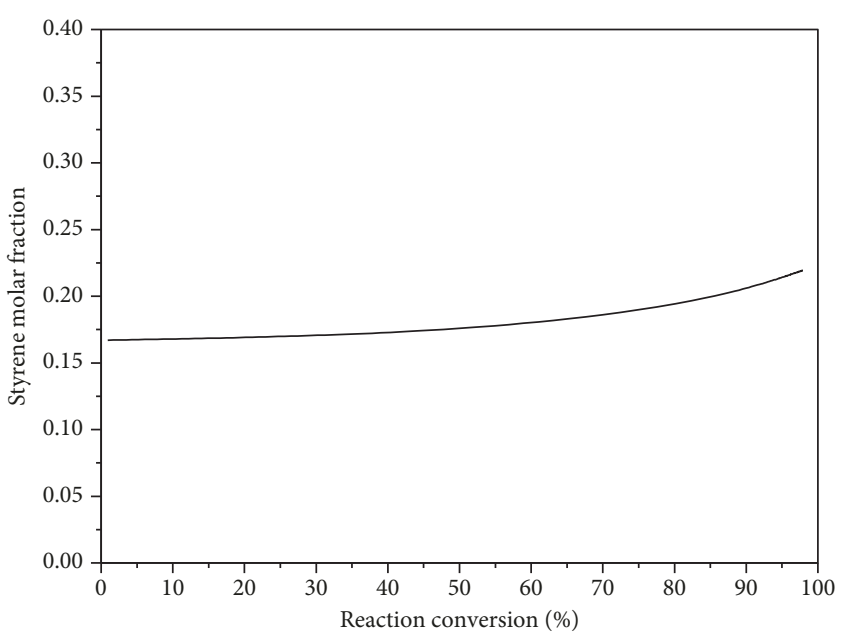

(b)

Figure 2: Conversion and composition profiles: gel and glass effects. $I=0.17 \mathrm{~mol}, M_{1}=1.54 \mathrm{~mol}, M_{2}=5.00 \mathrm{~mol}, T=85^{\circ} \mathrm{C}, r_{11}=0.472$, $r_{12}=0.454, r_{21}=0.472, r_{22}=0.454, s_{1}=0.412$, and $s_{2}=0.170[34]$.

where the critical free volume for termination is given by

$$
v_{f_{c}}^{T}=0.1856-0.2965 \cdot 10^{-3}(T-273.15) .
$$

In order to correct the propagation constant, $g_{P_{\mathrm{MMA}}}(T)$ is expressed in the following form $[38,39,42]$ :

$$
g_{P_{\mathrm{MMA}}}(T)=\left\{\begin{array}{l}
1, \quad \text { for } v_{f}>0.05 \\
7.1 \cdot 10^{-5} \exp \left(171.53 v_{f}\right), \quad \text { for } v_{f} \leq 0.05
\end{array}\right.
$$

For the styrene species, the gel effect correlation is expressed as a function of the styrene conversion $\left(x_{S}\right)$, as follows [39]:

$$
\begin{aligned}
& g_{T_{S}}(T)=\exp \left(-0.4404 x_{S}-6.362 x_{S}^{2}-0.1704 x_{S}^{3}\right), \\
& g_{P_{S}}(T)=1.0 .
\end{aligned}
$$

Figure 2 illustrates the simulation results for the S/MMA system. The copolymerization behavior is strongly affected when glass and gel effects are considered, exhibiting autoacceleration of the polymerization and copolymer composition drift. According to Figure 2(a), a maximum conversion limit equal to $98 \%$ is achieved and the molar fraction of styrene in the copolymer is lying in the interval from $17 \%$ to $22 \%$. It is also observed that the copolymer composition slightly changes at the beginning of the reaction when the conversion is below $40 \%$ and the viscosity effects are not pronounced.

Figure 3 illustrates the effect of the reaction temperature and the initiator concentration on the global conversion behavior. According to Figure 3(a) the conversion is significantly affected by the temperature, exhibiting a strong gel effect as the medium temperature is increased from $70^{\circ} \mathrm{C}$ to $90^{\circ} \mathrm{C}$. Simulations presented in Figure 3(b) were performed at $80^{\circ} \mathrm{C}$ and show that the global conversion is slightly affected by the initiator (benzoyl peroxide (BPO)) concentration, lying in the range from $85 \%$ to $91 \%$ when the $\mathrm{BPO}$ concentration is increased from $0.10 \mathrm{~mol}$ to $0.2 \mathrm{~mol}$.

Figure 4 illustrates the ability of the penultimate model to predict the experimental data of the bulk copolymerization of styrene and methyl methacrylate as provided by Jalili et al. [43]. According to Figure 4, the reaction conversion profile is satisfactory predicted by the penultimate model, which is able to represent typical monomer mass-transfer limitation that is responsible for a strong nonlinear kinetic behavior closely related to gel and glass effects.

3.2. Vinyl Acetate/Acrylic Acid Copolymerization. The effect of the penultimate monomeric unit of the growing polymer chains might also be important in vinyl acetate (VAc)/acrylic acid (AA) copolymerizations performed in dispersed medium such as suspension polymerization process. In a series of articles, Silva and coworkers [44-46] evaluated the suspension copolymerization of VAc/AA. According to the authors, the role of the penultimate effect in the kinetic mechanism of VAc/AA must be considered.

In order to evaluate the ability of equations (6) and (7) to predict the kinetic behavior of VAc/AA, copolymerization is fundamental to describe the partition of AA between the organic phase and the aqueous phase. For this reason, the AA partition coefficient must be included into the copolymerization model to determine the AA concentration throughout the reaction. Equations (14) and (15) represent the solubility of AA in water. It is very important to keep in mind that the amount of AA available for polymerization inside the organic droplets (dispersed into the aqueous phase) is different from the total amount of monomer added into the reactor $\left(M_{2}=M_{2}\right.$ aqueous $\left.+M_{2}{ }^{\text {organic }}\right)$. The amounts of 


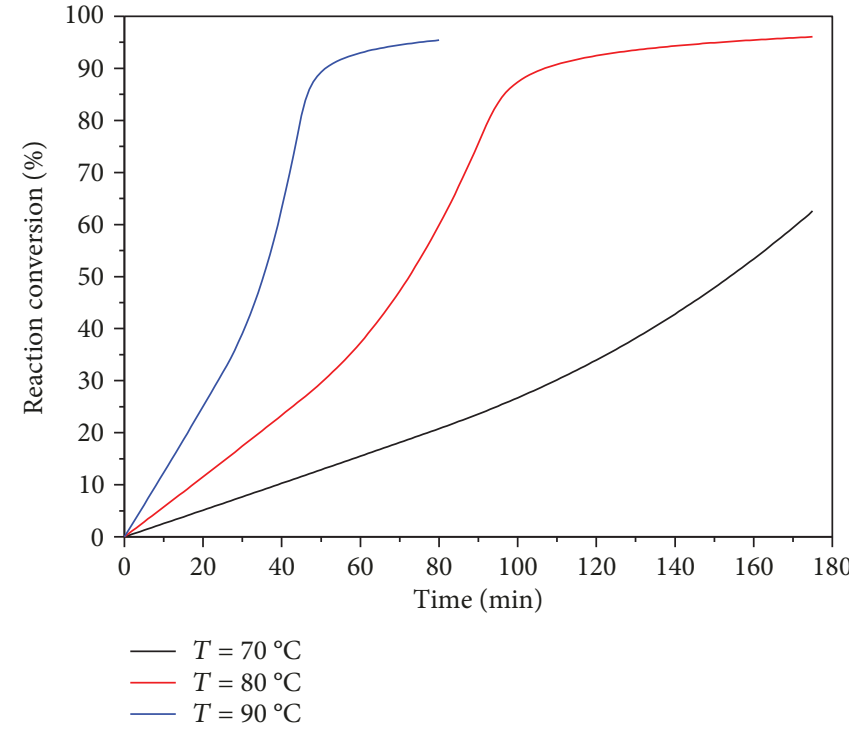

(a)

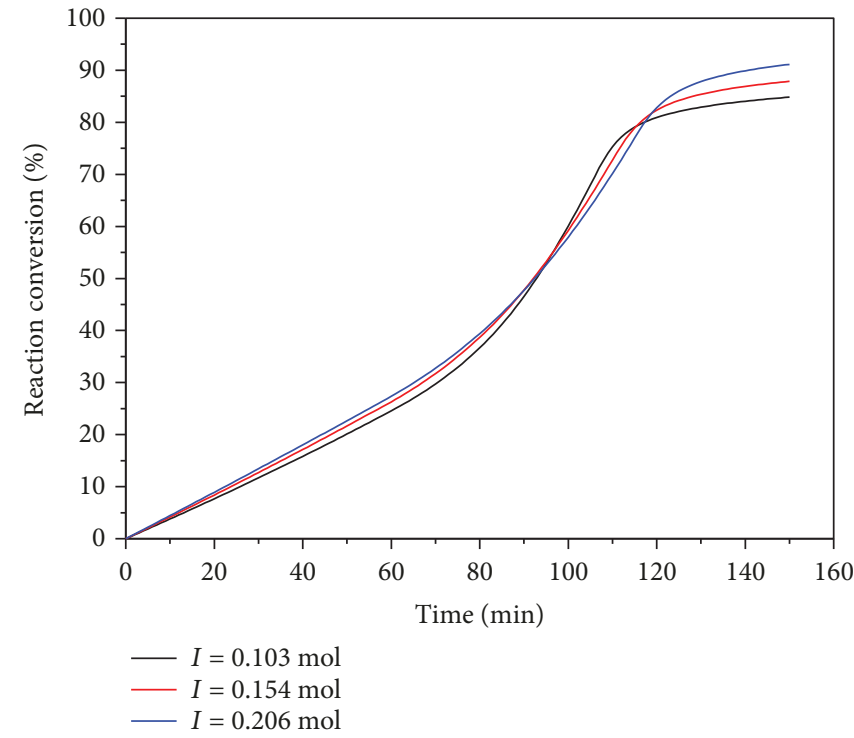

(b)

Figure 3: Effect of (a) temperature and (b) initiator concentration on the conversion profiles. $M_{1}=2.4 \mathrm{~mol}, M_{2}=9.25 \mathrm{~mol}, T=80^{\circ} \mathrm{C}$, $r_{11}=0.472, r_{12}=0.454, r_{21}=0.472, r_{22}=0.454, s_{1}=0.412$, and $s_{2}=0.170$ [34].

AA in the organic $\left(M_{2}{ }^{\text {organic }}\right)$ and aqueous $\left(M_{2}{ }^{\text {aqueous }}\right)$ phases is given as follows [46]:

$$
\begin{aligned}
M_{2}{ }^{\text {organic }} & =\frac{M_{2}}{1+K}, \\
M_{2}^{\text {aqueous }} & =\frac{K}{1+K} M_{2},
\end{aligned}
$$

where

$$
K=\alpha \frac{V^{\text {aqueous }}}{V^{\text {organic }}}
$$

where $V^{\text {organic }}$ is the volume of the organic phase and $V^{\text {aqueous }}$ corresponds to the volume of the aqueous phase.

The partition coefficient of AA considering the system in the system AA/VAc/water is represented as a function of both the aqueous AA composition and temperature in the following form [46]:

$$
\alpha\left(T,\left[M_{2}\right]^{I I}\right)=\left[A+B\left[M_{2}\right]^{I I}+\frac{C}{\left(\left[M_{2}\right]^{I I}\right)^{2}}\right]^{-1},
$$

where coefficients $\mathrm{A}, \mathrm{B}$, and $\mathrm{C}$ are temperature-dependent adjustable parameters, expressed as follows [46]:

$$
\begin{aligned}
& A=-16.67+0.455(T-273.15)-2.92 \cdot 10^{-3}(T-273.15)^{2}, \\
& B=23.02-0.594(T-273.15)+3.96 \cdot 10^{-3}(T-273.15)^{2}, \\
& C=0.317-9.02 \cdot 10^{-3}(T-273.15)+6.04 \cdot 10^{-5}(T-273.15)^{2} .
\end{aligned}
$$

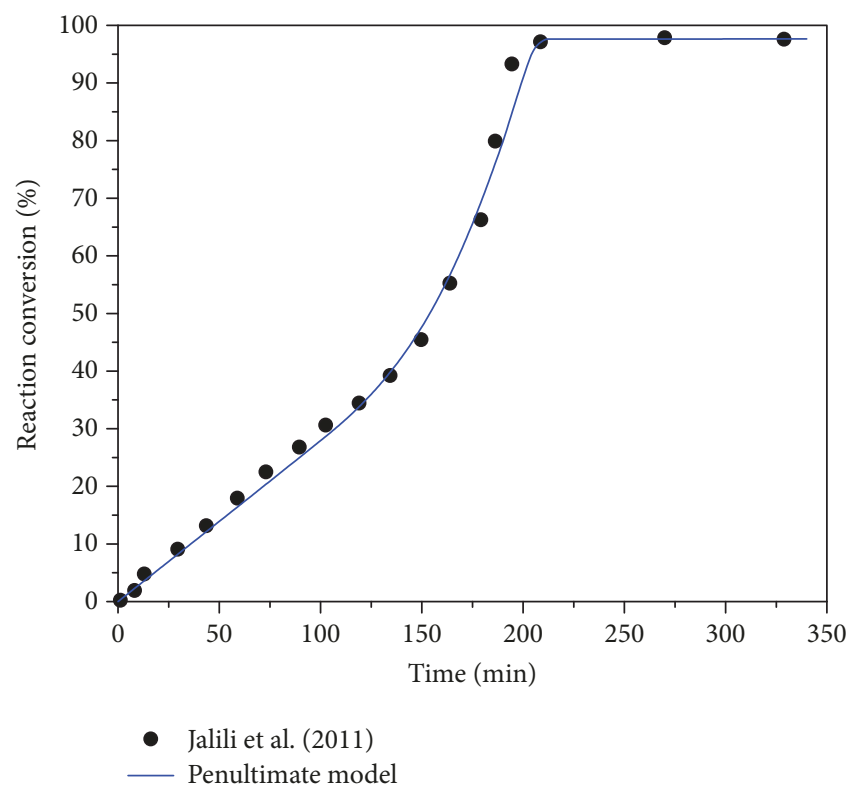

Figure 4: Penultimate model prediction of the styrene/methyl methacrylate bulk copolymerization carried out with BPO [43].

Table 2 presents the model parameters, and Figure 5 shows the prediction of the penultimate model (equations (6) and (7)) in comparison to experimental data provided by Silva et al. [45]. As depicted in Figure 5, the proposed model is able to describe experimental data of conversion and AA composition. Figure 6 illustrates the effect of the initiator amount on the kinetic behavior, when BPO inside the organic phase was varied from $0.004 \mathrm{~mol}$ to $0.021 \mathrm{~mol}$. The copolymerization conversion is significantly affected by the BPO concentration. According to simulation results, this 
TABLE 2: Model parameters used for simulation of vinyl acetate/acrylic acid system.

\begin{tabular}{|c|c|c|}
\hline Parameter & Unit & Reference \\
\hline$\rho_{1}=0.9584-1.3276 \cdot 10^{-3}(T-273.15)$ & $\mathrm{g} / \mathrm{cm}^{3}$ & {$[48]$} \\
\hline$\rho_{2}=1.0821-1.1969 \cdot 10^{-3}(T-273.15)$ & $\mathrm{g} / \mathrm{cm}^{3}$ & {$[45]$} \\
\hline$\rho_{3}=1.211-8.496 \cdot 10^{-4}(T-273.15)$ & $\mathrm{g} / \mathrm{cm}^{3}$ & {$[48]$} \\
\hline$\rho_{4}=1.22$ & $\mathrm{~g} / \mathrm{cm}^{3}$ & {$[49]$} \\
\hline$\rho_{w}=1.00066-7.35 \cdot 10^{-5}(T-273.15)-3.5 \cdot 10^{-6}(T-273.15)$ & $\mathrm{g} / \mathrm{cm}^{3}$ & {$[50]$} \\
\hline$k_{P_{11}}=3.2 \times 10^{7} \exp (-6300 / R T)$ & $\mathrm{L} /(\mathrm{mol} \cdot \mathrm{s})$ & {$[48]$} \\
\hline$k_{T_{11}}=3.7 \times 10^{9} \exp (-3200 / R T)$ & $\mathrm{L} /(\mathrm{mol} \cdot \mathrm{s})$ & {$[48]$} \\
\hline$k_{P_{22}}=8.4 \cdot 10^{2}$ & $\mathrm{~L} /(\mathrm{mol} \cdot \mathrm{s})$ & In this work \\
\hline$k_{T_{22}}=3.2 \cdot 10^{7}$ & $\mathrm{~L} /(\mathrm{mol} \cdot \mathrm{s})$ & In this work \\
\hline$k_{D}=1.7 \times 10^{14} \exp (-30000 / R T)$ & $s^{-1}$ & {$[51]$} \\
\hline$f=0.8$ & - & {$[48]$} \\
\hline
\end{tabular}

Subscript 1 is reserved for vinyl acetate, and subscript 2 is for acrylic acid. Subscripts 3 and 4 for the homopolymers based on vinyl acetate and acrylic acid, respectively.
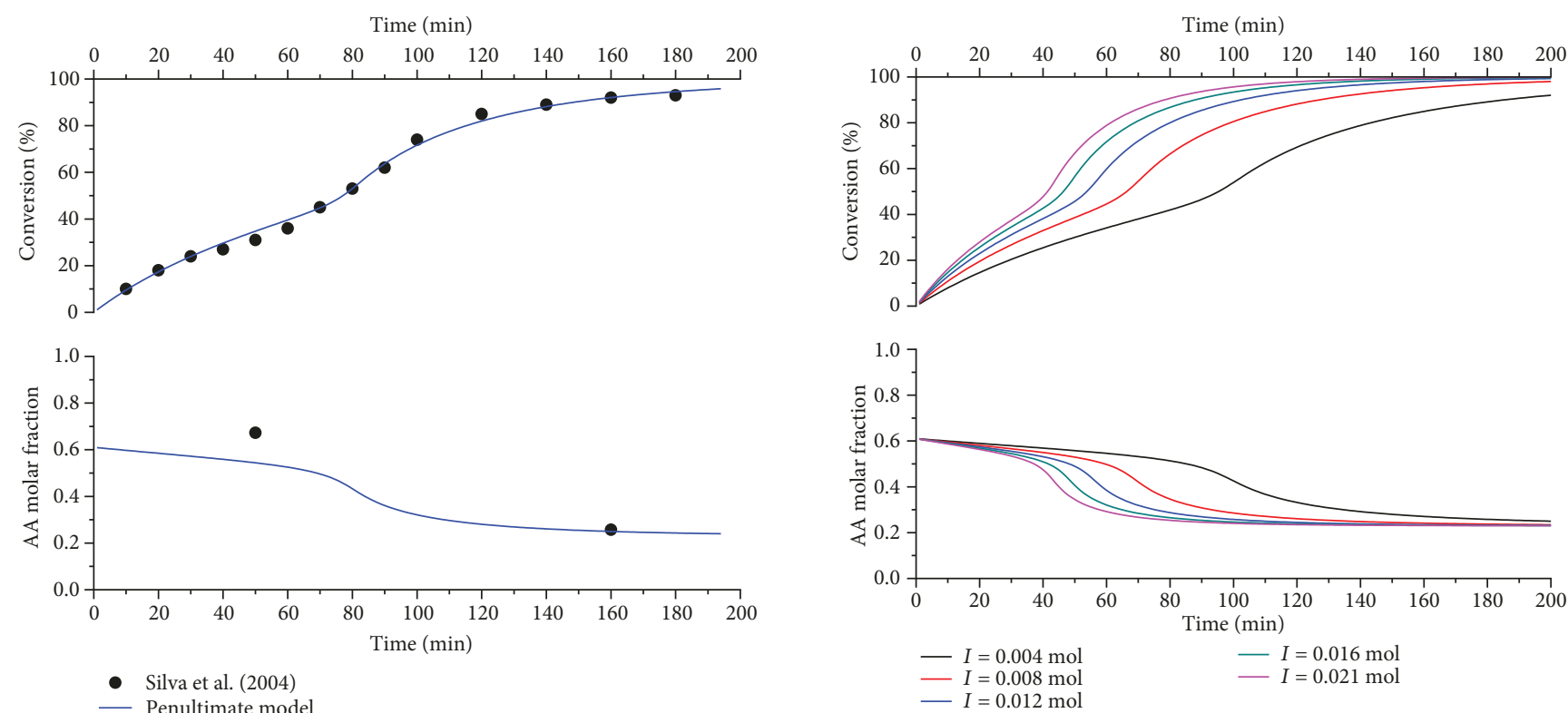

Figure 5: Penultimate model prediction for the vinyl acetate/acrylic acid copolymerization. $M_{1}=1.67 \mathrm{~mol}, M_{2}=0.50 \mathrm{~mol}, T=70^{\circ} \mathrm{C}$, $r_{11}=0.054, r_{12}=2.927, r_{21}=0.032, r_{22}=1.902, s_{1}=0.412$, and $s_{2}=1.0[52]$.

FIGURE 6: Effect of the initiator amount on the conversion and composition profiles. $M_{1}=1.67 \mathrm{~mol}, M_{2}=0.50 \mathrm{~mol}, T=70^{\circ} \mathrm{C}$, $r_{11}=0.054, r_{12}=2.927, r_{21}=0.032, r_{22}=1.902, s_{1}=0.412$, and $s_{2}=1.0[52]$.

kind of reaction is characterized by presenting an autoacceleration of the polymerization and significant drift of copolymer composition.

The synthesis of copolymer materials presenting homogeneous chemical composition throughout the reaction may be regarded as an important challenge in the polymerization field mainly when the copolymerization is carried out with from monomers that present very different reactivities. In order to avoid composition drift control, composition strategies should be implemented. In the particular case of VAc/AA copolymerization because of the complete solubility

of $\mathrm{AA}$ in the aqueous phase (AA is partitioned between the organic and the aqueous phases during the reaction course), semibatch operation mode can be successfully performed, as the aqueous phase can be used as a reservoir, supplying AA for the organic phase.

Based on the previous assumptions, semibatch copolymerization can be performed to keep the copolymer composition constant at the desired setpoint $\left(y_{\mathrm{AA}}{ }^{d}\right)$ value throughout reaction through manipulation of the feed flow rate of $\mathrm{AA}\left(F_{\mathrm{AA}}\right)$. AA feed rate profiles required to maintain AA molar fraction constant into the copolymer chains were 


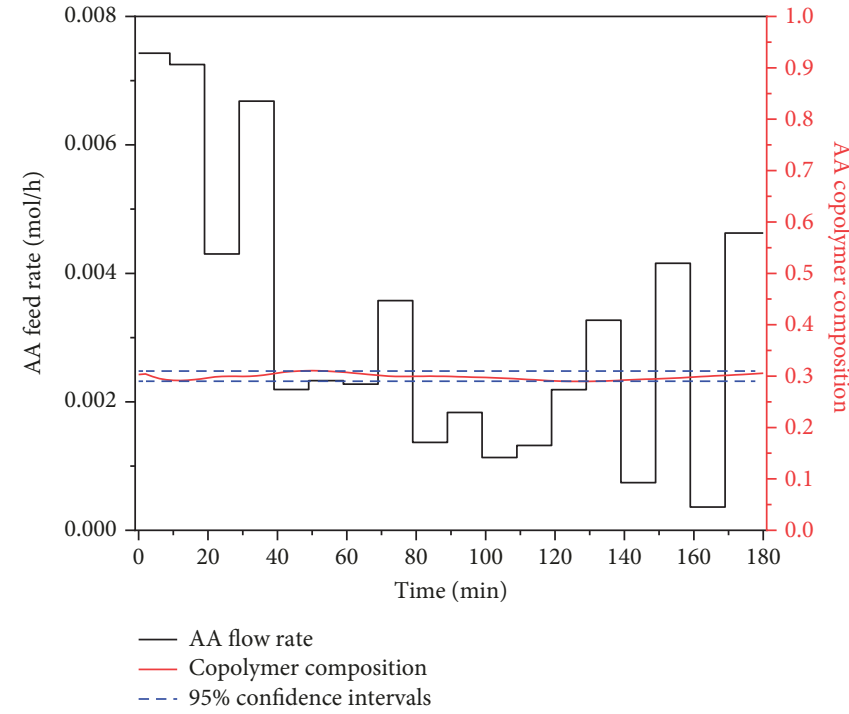

(a)

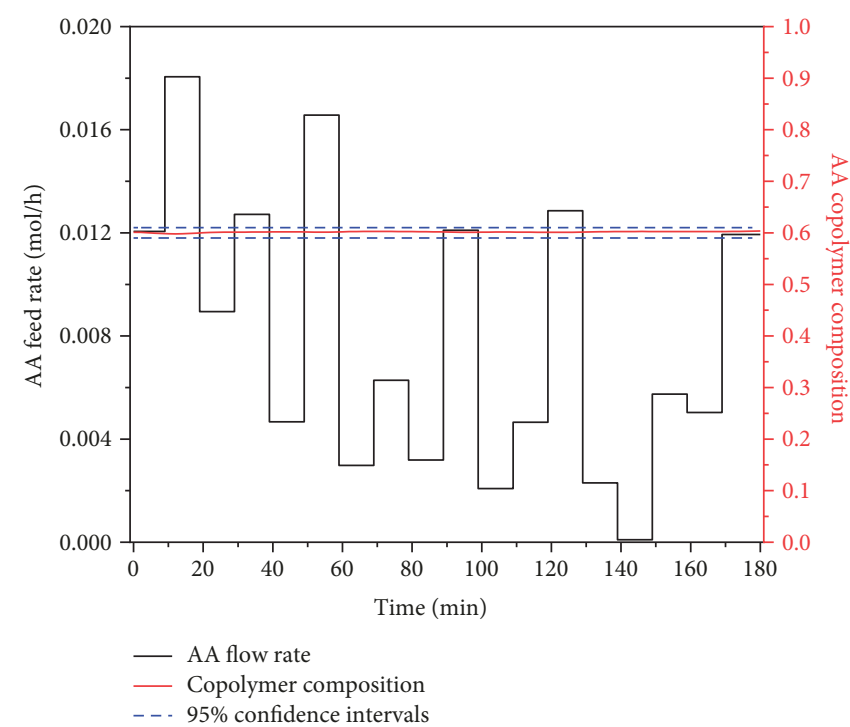

(b)

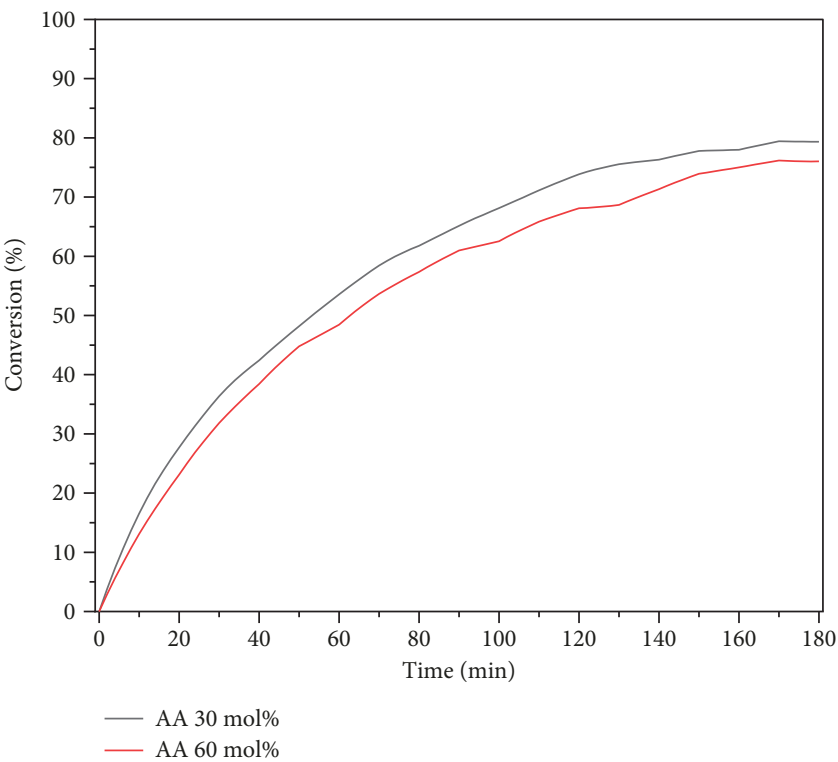

(c)

FIGURE 7: Dynamic behavior of vinyl acetate/acrylic acid suspension copolymerizations in semibatch operation mode. AA feed flow rate and AA copolymer composition profile for $y_{\mathrm{AA}}=30 \mathrm{~mol} \%$ (a) and $y_{\mathrm{AA}}=60 \mathrm{~mol} \%$ (b) and conversion profiles (c).

determined for discretized time intervals of 10 minutes. The optimization problem can be defined as follows:

$$
\begin{aligned}
& \min _{\frac{F_{\mathrm{AA}}}{\text { subject to }}} f=\sum_{i=1}^{\mathrm{ND}}\left(y_{i}-y_{i}^{d}\right)^{2}, \\
& l_{i} \leq u_{i}, \quad i=1,2, \ldots, m,
\end{aligned}
$$

where $y_{i}$ corresponds to the cumulative copolymer composition at each discretized sampling time $i, y_{i}^{d}$ is the desired copolymer composition at each discretized sampling time $i$, ND is the number of discretized sampling times in the control window of 10 minutes, $x_{i}$ is the manipulated variable at each discretized sampling time $i, f$ is the objective function that must be minimized, $u_{i}$ is the upper limit of the constraints, and $l_{i}$ is the lower limit of the constraints.

AA feed rate profiles were estimated based on stochastic optimization procedures with the Monte Carlo method [47]. Optimum candidates were estimated by generating random numbers in the following form:

$$
x_{i, j}=x_{i, j-1}+r_{i, j} \Delta_{i, j}, \quad i=1, \ldots, \mathrm{ND}, j=1, \ldots, \text { NITER },
$$

where $r_{i, j}$ are pseudorandom numbers uniformly distributed in the interval $(-1,1)$ and $\Delta_{i, j}$ defines a search interval for variable $i$ at iteration $j$. Dynamic trajectories of conversion and copolymer composition were computed after the generation 
of the candidate optimum solutions at iteration $j$, and the objective function was minimized.

Figure 7 shows the optimum AA feed rate profiles generated to keep the AA copolymer composition equal to $30 \mathrm{~mol} \%$ and $60 \mathrm{~mol} \%$ as well as global conversions predicted by the penultimate polymerization model. According to Figures 6(a) and 6(b), copolymers with homogeneous chemical composition at the desired setpoint values are easily obtained based on the proposed optimization procedure. The copolymer composition is kept within the upper control (UCL) and lower control (LCL) limits considering a $95 \%$ confidence interval and standard deviation equal to $1 \%$ related to the setpoint value of the AA molar fraction. It is important to note that because of the high consumption rates of the AA, the conversion trajectories are not affected by fluctuation of the AA feed operation, as shown in Figure 7(c).

\section{Conclusion}

A kinetic model of free-radical copolymerization of styrene and methyl methacrylate was proposed, taking into account the penultimate unit effect. It was shown that the addition copolymerization reactions can be properly simulated by using the proposed penultimate polymerization model, being suitable to evaluate strong nonlinear behavior that takes place due to the presence of viscosity effects related to important kinetic phenomena such as autoacceleration of the polymerization, copolymer composition drift, diffusion, and heat-transfer limitations. Copolymer with homogeneous composition along the whole polymerization time can be successfully obtained through manipulation of the AA feed flow rate based on stochastic optimization procedures.

\section{Data Availability}

The data used to support the findings of this study are included within the article.

\section{Conflicts of Interest}

The author declares no conflict of interest.

\section{Acknowledgments}

The authors thank the Coordenação de Aperfeiçoamento de Pessoal de Nível Superior (CAPES) and Conselho Nacional de Desenvolvimento Científico e Tecnológico (CNPq) for providing scholarships and financial support.

\section{References}

[1] F. R. Mayo and F. M. Lewis, "Copolymerization. I. A basis for comparing the behavior of monomers in copolymerization; the copolymerization of styrene and methyl methacrylate," Journal of the American Chemical Society, vol. 66, no. 9, pp. 1594-1601, 1944.

[2] E. Merz, T. Alfrey, and G. Goldfinger, "Intramolecular reactions in vinyl polymers as a means of investigation of the propagation step," Journal of Polymer Science, vol. 1, no. 2, pp. 75-82, 1946.
[3] N. A. Dotson, R. Galván, R. L. Laurence, and M. Tirrel, Polymerization Process Modeling, Wiley-VCH Publishers, New York, NY, USA, 1996.

[4] G. Odian, Principles of Polymerization, John Wiley \& Sons, Inc., Hoboken, NJ, USA, 4th edition, 2004.

[5] T. Fukuda, Y. D. Ma, H. Inagaki, and K. Kubo, "Penultimateunit effects in free-radical copolymerization," Macromolecules, vol. 24, no. 2, pp. 370-375, 1991.

[6] M. L. Coote and T. P. Davis, "The mechanism of the propagation step in free-radical copolymerisation," Progress in Polymer Science, vol. 24, no. 9, pp. 1217-1251, 1999.

[7] M. L. Coote, T. P. Davis, and L. Radom, "Effect of the penultimate unit on radical stability and reactivity in free-radical polymerization," Macromolecules, vol. 32, no. 9, pp. 29352940, 1999.

[8] T. P. Davis, "The mechanism of propagation in free-radical copolymerization," Journal of Polymer Science Part A: Polymer Chemistry, vol. 39, no. 5, pp. 597-603, 2001.

[9] T. Fukuda, A. Goto, Y. Kwak, C. Yoshikawa, and Y.-D. Ma, "Penultimate unit effects in free radical copolymerization," Macromolecular Symposia, vol. 182, no. 1, pp. 53-64, 2002.

[10] J. P. A. Heuts, R. G. Gilbert, and I. A. Maxwell, "Penultimate unit effect in free-radical copolymerization," Macromolecules, vol. 30, no. 4, pp. 726-736, 1997.

[11] H. Gao, L. H. Oakley, I. A. Konstantinov, S. G. Arturo, and L. J. Broadbelt, "Acceleration of kinetic Monte Carlo method for the simulation of free radical copolymerization through scaling," Industrial \& Engineering Chemistry Research, vol. 54, no. 48, pp. 11975-11985, 2015.

[12] S. I. Kuchanov, A. N. Bogdanov, and K. V. Tarasevich, "Theoretical consideration of phase behavior of the products of free-radical copolymerization described by the penultimate model," Macromolecular Theory and Simulations, vol. 24, no. 5, pp. 442-459, 2015.

[13] S. Hamzehlou, Y. Reyes, R. Hutchinson, and J. R. Leiza, "Copolymerization of $n$-butyl scrylate and styrene: terminal vs penultimate model," Macromolecular Chemistry and Physics, vol. 215, no. 17, pp. 1668-1678, 2014.

[14] P. C. Deb, "Determination of penultimate model reactivity ratios and their non-uniqueness," Polymer, vol. 48, no. 2, pp. 432-436, 2007.

[15] D. J. T. Hill, J. H. O'Donnell, and P. W. O'Sullivan, “Analysis of the mechanism of copolymerization of styrene and acrylonitrile," Macromolecules, vol. 15, no. 4, pp. 960-966, 1982.

[16] S. A. Jones, G. S. Prementine, and D. A. Tirrell, "Model copolymerization reactions. Direct observation of a "penultimate effect" in a model styrene-acrylonitrile copolymerization," Journal of the American Chemical Society, vol. 107, no. 18, pp. 5275-5276, 1985.

[17] D. A. Cywar and D. A. Tirrell, "Model copolymerization reactions. Determination of the relative rates of addition of styrene and acrylonitrile to the 1-phenylethyl radical," Macromolecules, vol. 19, no. 12, pp. 2908-2911, 1986.

[18] D. J. T. Hill, A. P. Lang, J. H. O'Donnell, and P. W. O'Sullivan, "Determination of reactivity ratios from analysis of triad fractions-analysis of the copolymerization of styrene and acrylonitrile as evidence for the penultimate model," European Polymer Journal, vol. 25, no. 9, pp. 911915, 1989. 
[19] A. Kaim, "Application of the monomer reactivity ratios to the kinetic-model discrimination and the solvent-effect determination for the styrene/acrylonitrile monomer system," Journal of Polymer Science Part A: Polymer Chemistry, vol. 38, no. 5, pp. 846-854, 2000.

[20] P. Cieplak, E. Megiel, and A. Kaim, "Penultimate unit effects in the free-radical copolymerization of styrene with acrylonitrile according to theoretical thermochemistry," Journal of Polymer Science Part A: Polymer Chemistry, vol. 40, no. 21, pp. 35923603, 2002.

[21] R. A. Hutchinson, J. H. McMinn, D. A. Paquet, S. Beuermann, and C. Jackson, "A pulsed-laser study of penultimate copolymerization propagation kinetics for methyl methacrylate/nbutyl acrylate," Industrial \& Engineering Chemistry Research, vol. 36, no. 4, pp. 1103-1113, 1997.

[22] D. J. Arriola, M. Bokota, R. E. Campbell Jr. et al., "Penultimate effect in ethylene-styrene copolymerization and the discovery of highly active ethylene-styrene catalysts with increased styrene reactivity," Journal of the American Chemical Society, vol. 129, no. 22, pp. 7065-7076, 2007.

[23] L. H. Yee, J. P. A. Heuts, and T. P. Davis, "Copolymerization propagation kinetics of dimethyl itaconate and styrene: strong entropic contributions to the penultimate unit effect," Macromolecules, vol. 34, no. 11, pp. 3581-3586, 2001.

[24] S. Losio, P. Stagnaro, T. Motta, M. C. Sacchi, F. Piemontesi, and M. Galimberti, "Penultimate-unit effect in ethene/4methyl-1-pentene copolymerization for a "sequential" distribution of comonomers," Macromolecules, vol. 41, no. 4, pp. 1104-1111, 2008.

[25] Y. Inaki, S. Hirose, K. Yasufuku, S. I. Nozakura, and S. Murahashi, "Penultimate unit effect in the radical copolymerization of $\alpha$-, $\beta$-alkylstyrenes and cycloalkenes with acrylonitrile," Polymer Journal, vol. 2, no. 4, pp. 481-488, 1971.

[26] T. Fukuda, Y. D. Ma, and H. Inagaki, "Free-radical copolymerization. 3. Determination of rate constants of propagation and termination for styrene/methyl methacrylate system. A critical test of terminal-model kinetics," Macromolecules, vol. 18, no. 1, pp. 17-26, 1985.

[27] Y. D. Ma, T. Fukuda, and H. Inagaki, "Free-radical copolymerization. 4. Rate constants of propagation and termination for p-chlorostyrene/methyl acrylate system," Macromolecules, vol. 18, no. 1, pp. 26-31, 1985.

[28] M. S. Kim and R. Faust, "Penultimate effect in the initiation of the cationic polymerization of isobutylene: kinetic study of initiation with (3-chloro-1,1,3-trimethylbutyl)benzene," Macromolecules, vol. 35, no. 13, pp. 5320-5322, 2002.

[29] S. Iwatsuki, A. Kondo, and H. Harashina, "Free radical copolymerization behavior of methyl $\alpha$-(trifluoromethyl)acrylate and $\alpha$-(trifluoromethyl)acrylonitrile: penultimate monomer unit effect and monomer reactivity parameters," Macromolecules, vol. 17, no. 12, pp. 2473-2479, 1984.

[30] W. G. Barb, "Effect of nonterminal monomer units on the reactivity of polymeric free radicals," Journal of Polymer Science, vol. 11, no. 2, pp. 117-126, 1953.

[31] A. Habibi and E. Vasheghani-Farahani, "Bayesian modeling and Markov chain Monte Carlo simulations for a kinetic study of homo- and co- polymerization systems," Macromolecular Theory and Simulations, vol. 16, no. 3, pp. 269-294, 2007.

[32] R. G. Fordyce and G. E. Ham, "Copolymerization. VIII. Reactivity of fumaronitrile in vinyl copolymerization," Journal of the American Chemical Society, vol. 73, no. 3, pp. 1186$1189,1951$.
[33] G. E. Ham, "Reactivity of polar monomers in copolymerization," Journal of Polymer Science, vol. 14, no. 73, pp. 87-93, 1954.

[34] A. L. Burke, T. A. Duever, and A. Penlidis, "Discriminating between the terminal and penultimate models using designed experiments: an overview," Industrial \& Engineering Chemistry Research, vol. 36, no. 4, pp. 1016-1035, 1997.

[35] D. Li, J. R. Leiza, and R. A. Hutchinson, "High temperature free radical copolymerization with depropagation and penultimate kinetic effects," Macromolecular Theory and Simulations, vol. 14, no. 9, pp. 554-559, 2005.

[36] D. Li, N. Li, and R. A. Hutchinson, "High-temperature free radical copolymerization of styrene and butyl methacrylate with depropagation and penultimate kinetic effects," Macromolecules, vol. 39, no. 13, pp. 4366-4373, 2006.

[37] A. N. Nikitin and R. A. Hutchinson, "Effect of intramolecular transfer to polymer on stationary free radical polymerization of alkyl acrylates, 4-consideration of penultimate effect," Macromolecular Rapid Communications, vol. 30, no. 23, pp. 1981-1988, 2009.

[38] A. D. Schmidt and W. H. Ray, "The dynamic behavior of continuous polymerization reactors-I: isothermal solution polymerization in a CSTR," Chemical Engineering Science, vol. 36, no. 8, pp. 1401-1410, 1981.

[39] G. Kalfas, H. Yuan, and W. H. Ray, "Modeling and experimental studies of aqueous suspension polymerization processes. 2 . Experiments in batch reactors," Industrial \& Engineering Chemistry Research, vol. 32, no. 9, pp. 1831-1838, 1993.

[40] L. R. Petzold, "A description of DASSL: a differential algebraic system solver," Report SAND82-8637, Sandia National Laboratory, 1982.

[41] G. A. O'Neil, M. B. Wisnudel, and J. M. Torkelson, “An evaluation of free volume approaches to describe the gel effect in free radical polymerization," Macromolecules, vol. 31, no. 14, pp. 4537-4545, 1998.

[42] S. X. Zhang and W. H. Ray, "Modeling and experimental studies of aqueous suspension polymerization processes. 3 . Mass-transfer and monomer solubility effects," Industrial \& Engineering Chemistry Research, vol. 36, no. 4, pp. 13101321, 1997.

[43] K. Jalili, F. Abbasi, and M. Nasiri, "Copolymerization of styrene and methyl methacrylate. Part I: experimental kinetics and mathematical modeling," Polymer, vol. 52, no. 19, pp. 4362-4376, 2011.

[44] F. M. Silva, E. L. Lima, and J. C. Pinto, “Acrylic acid/vinyl acetate suspension copolymerizations. I. Partition coefficients for acrylic acid," Journal of Applied Polymer Science, vol. 93, no. 3, pp. 1077-1088, 2004.

[45] F. M. Silva, E. L. Lima, and J. C. Pinto, "Acrylic acid/vinyl acetate suspension copolymerizations. 2. Modeling and experimental results," Industrial \& Engineering Chemistry Research, vol. 43, no. 23, pp. 7324-7342, 2004.

[46] F. M. Silva, E. L. Lima, and J. C. Pinto, "Control of the copolymer composition in suspension copolymerization reactions," Industrial \& Engineering Chemistry Research, vol. 43, no. 23, pp. 7312-7323, 2004.

[47] B. Hesselbo and R. B. Stinchcombe, "Monte Carlo simulation and global optimization without parameters," Physical Review Letters, vol. 74, no. 12, pp. 2151-2155, 1995.

[48] J. C. Pinto and W. H. Ray, "The dynamic behavior of continuous solution polymerization reactors-VII. Experimental 
study of a copolymerization reactor," Chemical Engineering Science, vol. 50, no. 4, pp. 715-736, 1995.

[49] R. A. Orwoll and Y. S. Chong, "Poly(acrylic acid)," in Polymer Data Handbook, pp. 252-253, Oxford University Press, Oxford, UK, 1999.

[50] R. H. Perry and D. W. Green, Perry's Chemical Engineers' Handbook, McGraw-Hill, New York, NY, USA, 7th edition, 1997.

[51] G. Kalfas and W. H. Ray, "Modeling and experimental studies of aqueous suspension polymerization processes. 1. Modeling and simulations," Industrial \& Engineering Chemistry Research, vol. 32, no. 9, pp. 1822-1830, 1993.

[52] P. C. Deb, "Generalized method for determination of penultimate model reactivity ratios and analysis of data," Polymer, vol. 48, no. 17, pp. 4932-4935, 2007. 


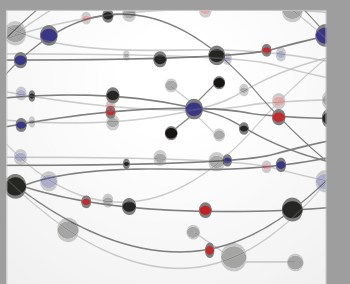

The Scientific World Journal
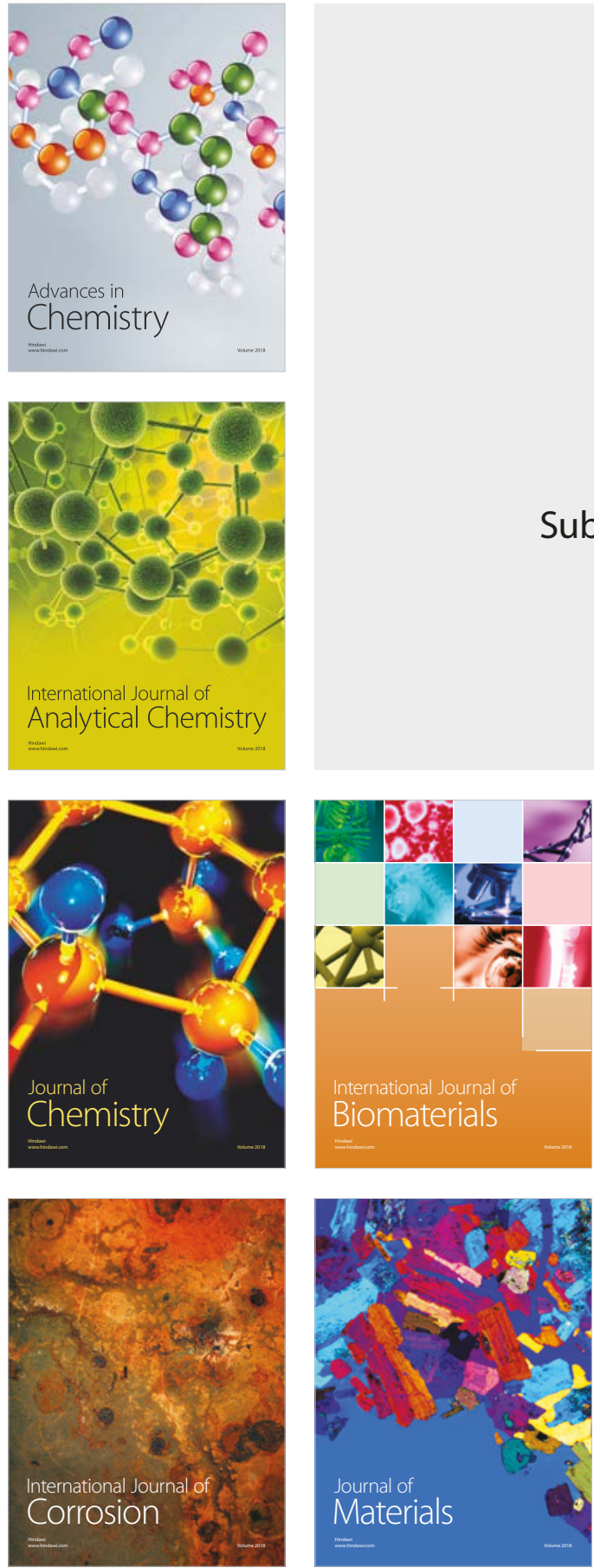

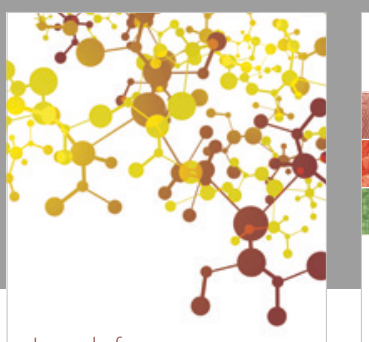

Journal of

Applied Chemistry
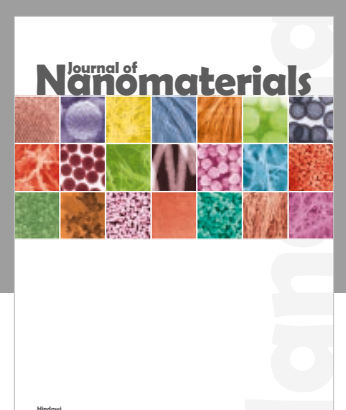

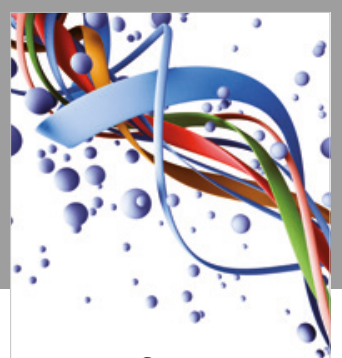

Scientifica

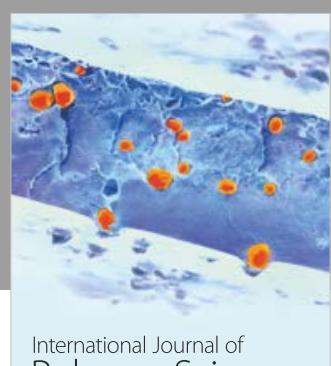

Polymer Science

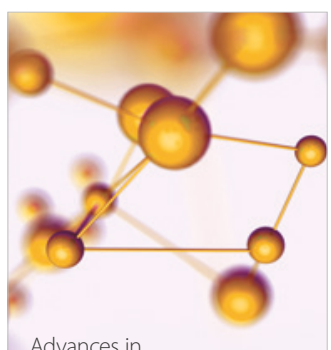

Physical Chemistry
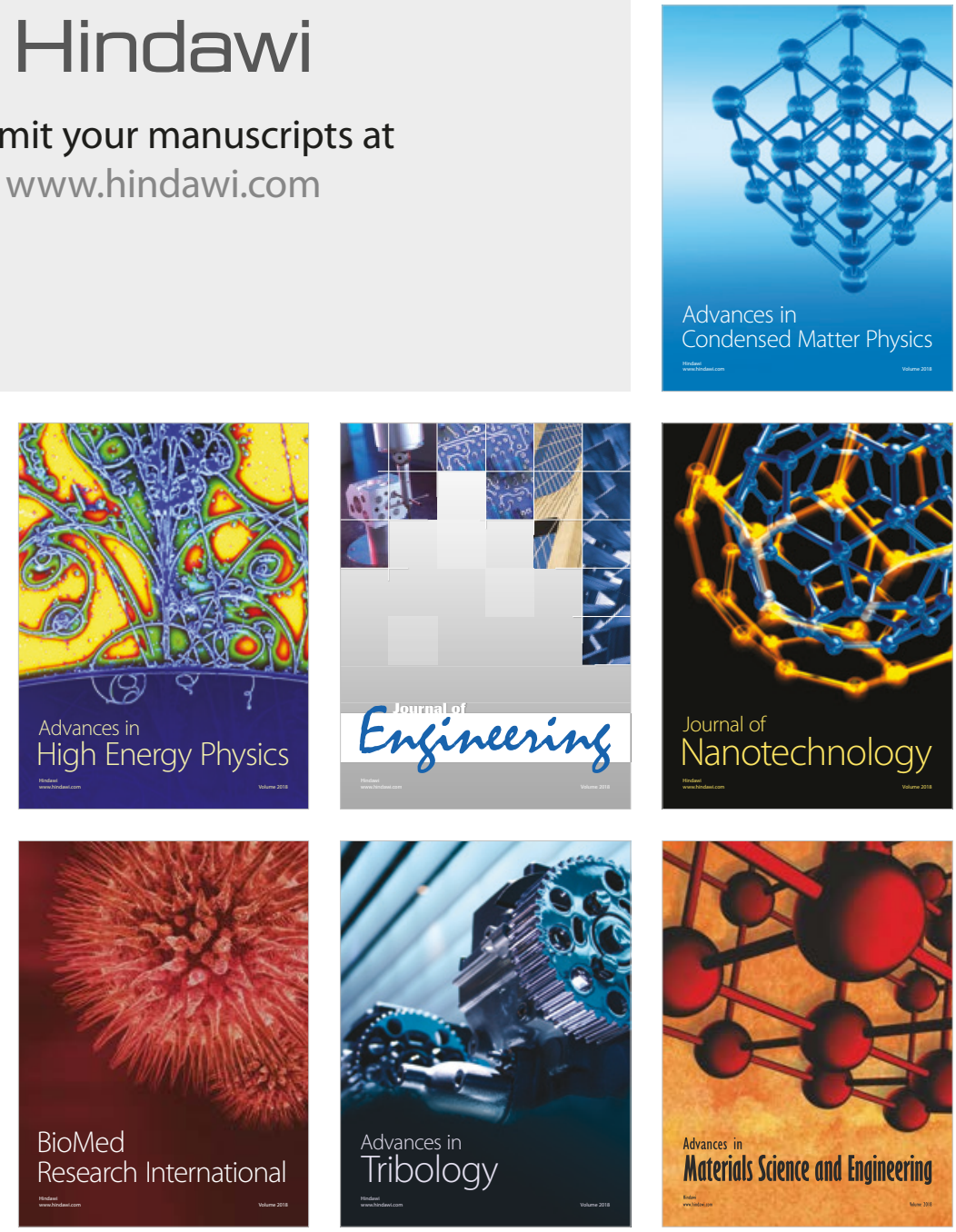